\title{
Artur Azevedo e a arte do soneto dramático
}

\author{
Pedro Marques
}

A melhor acomodação para Artur Azevedo (1855-1908) na literatura, arte ou cultura brasileira é o teatro. Como autor, crítico ou articulador reconhece-se seu relevo para a evolução de nossa comédia. Personalidade certa nos trabalhos que documentam a história dos palcos no Brasil pôde, no entanto, protagonizar diversos outros papéis, característica nada estranha, aliás, ao homem de letras de sua época. De olho nesse trânsito, sinalizo aqui algumas de suas visitas à poesia, que, fortuitamente, o seduziu ao curso da carreira literária.

Divulgados imprensa adentro e até hoje ainda em parte reunidos, seus versos despertam interesse de poucos estudiosos. Mesmo assim, pela contemporaneidade ao parnasianismo, Artur Azevedo garantiu cadeira nas duas principais obras que antologizam o movimento: a Antologia dos Poetas Brasileiros da Fase Parnasiana (1938), de Manuel Bandeira, e Poesia Parnasiana - Antologia (1967), de Péricles Eugênio da Silva Ramos. Cronologicamente, Artur pertence ao grupo de Machado de Assis (18391908), Alberto de Oliveira (1857-1937), Raimundo Correia (1859-1911) e Olavo Bilac (1865-1918). Demonstrar, no entanto, o quanto sua poesia interage com as disposições poéticas desse quarteto tem sido um nó que este artigo começa apenas a afrouxar.

Num longo processo que vem do período romântico, o escritor parnasiano consolida-se nos meios de produção literária, chamando para si o trabalho intelectual e a difícil tarefa de construir para um país recente o padrão de instrução e civilidade. A geração de Artur Azevedo criou a Academia Brasileira de Letras (ABL), assumiu cargos em jornais e na educação, promoveu como nunca a crítica e as conferências literárias. Com ou sem inspiração, o artista ganha consciência de sua responsabilidade sócio-cultural. É preciso, portanto, atenuar apreciações que enxergam no parnasianismo apenas "distanciamento entre o escritor e o público" (SODRÉ, 1964, p. 453). Para Paulo Franchetti dá-se exatamente o inverso: "poucas vezes pôde-se observar, na história da leitura no Brasil, uma consonância tão intensa entre os ideários dos principais escritores do momento e o público de que dispunham" (FRANCHETTI, 2007, p. 31). O poeta fortalece suas atribuições à proporção que se profissionaliza, por isso tende a repelir o verso amador produto das horas vagas do advogado, do médico, do engenheiro ou do político. A dedicação remunerada substitui cada vez mais o entusiasmo, o artífice pleiteia o espaço do bardo eventual.

O parnasianismo brasileiro é de inspiração francesa. Porém, os reparos à estética romântica na França são por aqui redimensionados. Na percepção de Lêdo Ivo "os preceitos de impassibilidade, da impersonalidade, uma das recomendações básicas da escola, foram belamente desrespeitados pelos nossos parnasianos, os quais 
não trepidaram em expor a sua subjetividade, tornada objetividade pelo processo criador" (IVO, 2004, p. 523). No Brasil não se interrompe, por exemplo, a frente nacionalista que, com o romantismo, norteia a construção de uma identidade fundada na natureza exuberante, na língua melodiosa, no povo entre selvagem e civilizado rumo à prosperidade. Mas a tônica localista é amenizada com doses de cosmopolitismo - bastante ameno se comparado ao do simbolismo - em que pesa a mão de Machado de Assis que, tutor do grupo, ensinava: "um poeta não é nacional só porque insere nos seus versos muitos nomes de flores ou aves do país" (ASSIS, 1997, p. 27).

$O$ poeta deveria enfrentar todo assunto, daí a tendência parnasiana englobar uma gama de temas. Argumentos eróticos, bélicos, mitológicos, históricos, naturalistas, infantis, cívicos, o que conseguissem dizer com definição de som e clareza de imagem. O enquadramento do objeto escolhido precisava mostrar volume e movimento para alcançar beleza. Esse esforço por objetividade, para Ivan Teixeira, acaba retomando "o preceito horaciano do ut pictura poesis", segundo o qual poesia e pintura guardariam analogias (TEIXEIRA, 1997, p. 19). A técnica apurada, as descrições com vistas à imparcialidade, o trabalho e a pesquisa formal, o estudo rigoroso dos materiais selecionados coíbem a facilidade da escrita. O culto à inspiração arrefece, só laborando o poeta consegue poemas bem resolvidos.

Nesse contexto, Artur Azevedo contribui com a nota cômica que, a rigor, somente ele desenvolveu com método. Olavo Bilac em Pimentões (1897) e Lira Acaciana (1900), por exemplo, soube com sucesso fazer rir sem, no entanto, investir sua energia vital nessa esfera. Já para Artur, a comicidade ultrapassa a escrita de circunstância; é a lente que define o universo sobre o qual se debruça, a condição para discutir toda pauta. Mesmo a tensão entre cosmopolitismo e nacionalismo, candente à época, será expressa de modo engraçado, sobretudo porque deslocada para o campo do galanteio barato.

Patriotismo

Como é bela, meu Deus, a brasileira!

Que doçura! Que mel! Que singeleza!

E a francesa? Jesus! Ai! A francesa!

Não pode haver mulher mais feiticeira.

E a italiana então? Essa é a primeira:

A espanhola, porém, tem mais nobreza!

E a gravidade da mulher inglesa?

E a alemã discreta e sobranceira?

E a circassiana que derrota, Com fama universal a mais bonita, E que ao mais sábio faz ficar idiota? 
E a húngara? A saxônia? A moscovita?...

Está dito: sou muito patriota,

Mas tenho o coração cosmopolita!

\section{(AZEVEDO, 1909)}

A pouca crítica sobre a poesia de Artur Azevedo realça a habilidade para criar situações divertidas, para lances irônicos ora brandos, ora mordazes. Jayme de Barros não tem dúvida, o apelida de "malicioso" (BARROS, 1944, p.107). "Tempera seus versos, define Péricles Eugênio da Silva Ramos, (...) com largo e sadio bom humor, que os singulariza em meio à poesia da época. Embora dotado para farpear, satirizando, foi no seu riso sem maldade que o poeta alcançou sua feição mais característica" (RAMOS, 1967, p. 69)

Alfredo Bosi fala em paródia dos "ultra-românticos" e "retrato fiel da sociedade carioca", as quais teriam rivalizado com a "gravidade burocrática com que posavam os medalhões parnasianos” (BOSI, 1994, p. 230). Luciana Stegagno-Picchio vai além, para ela, as sátiras de Artur antecipariam os "poemas-piadas de modernistas e surrealistas brasileiros e portugueses", num espírito de "vanguarda bem diferente da séria conceptuosidade de seus irmãos no Parnaso” (STEGAGNO-PICCHIO, 2004, p. 318). De seu ponto vista, João Pacheco destaca "a veia cômica, bonachona, descuidada, puramente à flor da pele, a que dá forma o verso fácil e, não raro, incolor". E ajunta as "qualidades" e "defeitos" de Artur: "a idéia graciosa, o estilo solto, ausência de matizes, um todo que mais diverte do que emociona" (PACHECO, s/d, p. 113).

A suposição geral dos comentários toma o registro espirituoso ou maledicente de Artur Azevedo como superficial na essência, como se fosse elementar divertir e entreter. No fundo, o gênero satírico, ao qual se filia grande parte dessa poesia, jamais é talhado para comover, mas para desprender o riso com reflexão crítica, à medida que ridiculariza algo ou alguém. O realismo desse segmento é lato senso; o vanguardismo inexiste. Da mesma maneira, por trás do efeito leviano ou de distração técnica, acaso sentido em poemas da espécie, costuma operar, via de regra, a seleção rigorosa de preceitos afinados ao propósito da composição, como de resto se espera de quem manipule a elegia ou lírica-amorosa.

Artur Azevedo pôde exercitar o humor comedido à maneira da série "Spleen e Charutos”, de Álvares de Azevedo (1831-1852). Compare-se, em especial, o soneto a seguir com o poema "Relógios e Beijos" do poeta romântico. Para melhorar o dormitório, desagradável sem a mulher, um eu lírico entediado procura enfeitá-lo com flores. O resultado, porém, é o oposto do aguardado, dando ao ambiente aspecto semelhante ao de um velório. A falta do ente desejado amplifica-se por todo o cômodo. Quando a amante está ausente, o desespero é tamanho que até os objetos inanimados sofrem. Trata-se de um momento particularmente lírico no poeta que, ainda assim, debocha da doença reiterada na poesia do XIX: o spleen ou mal du siècle. 
O Relógio

Quando não vens, formosa desumana, E, saudoso de ti, sem ti me deito,

Fica tão espaçoso o nosso leito,

Que me parece o campo de Sant'Ana!

Quando não vens, oh! pálida tirana,

Torna-se lúgubre o quartinho estreito!

Com muitas flores, flor, debalde o enfeito:

Falta-lhe a flor das flores soberana.

Se vens, é natural que isso me apraza;

Mas, se não vens, quanta amargura, quanta

As próprias coisas sentem nesta casa!

É o relógio, porém, que mais me espanta,

Pois se não vens, o mísero se atrasa,

$\mathrm{E}$, se vens, o ditoso se adianta!

\section{(AZEVEDO, 1909)}

Mas o escritor soube arremessar farpas contra lugares comuns do romantismo. Nesses instantes, a personalidade do inventivo comediógrafo traz mais nitidamente para a poesia o sarcasmo e malícia que tanto o distinguiram nos palcos. No soneto a seguir, pinta-se um noivo com caracteres negativos: feio, estúpido, arrogante por possuir o título de "comendador", orgulhoso porque uma espécie de empresário ou pequeno banqueiro do período ("negociante"). Ridículo, esse noivo incorpora até o perfil físico do poeta; presume-se vate por saber arranhar uns poucos clichês (“arsenal”) românticos na hora de declarar amor.

Deslumbrado por amadas idealizadas, mesmo quando já mortas, sugere-se que esse tipo específico de bardo, quando diante da chance de concretizar os desejos, vira de lado e dorme. Atitude oposta ao tipo de voz poética construída por um Carvalho Junior (1855-1879), para quem Artur dedica oportunamente o soneto. Carvalho foi dos primeiros, entre nós, a conquistar algum sucesso agredindo as convenções da poesia romântica. Nos poucos poemas que deixou o comum é o ato sexual se concretizar, substituindo-se a melancolia pela ação. Saem de cena as "virgens pálidas, cloróticas", "escritas num acesso de histerismo", para a entrada das mulheres de carne, preferíveis porque com "saúde" e "vida enfim" (JUNIOR, 1879). 
Remate de Males - 28(1) - jan./jun. 2008

Miserável

A Carvalho Junior

O noivo, como noivo, é repugnante:

Materialão, estúpido, chorudo,

Arrotando, a propósito de tudo,

O ser comendador e negociante.

Tem a viuvinha, a noiva interessante,

Todo o arsenal de um poeta guedelhudo:

Alabastro, marfim, coral, veludo,

Azeviche, safira e tutti quanti.

Da misteriosa alcova a porta geme,

O noivo dorme n'um lençol envolto...

Entra a viuvinha, a noiva... Oh, céu, contém-me!

Ela deita-se... espera... Qual! Revolto,

O leito estala... Ela suspira... freme...,

E o miserável dorme a sono solto!...

\section{(AZEVEDO, 1914)}

No plano da revisão formal ou estilística, Machado de Assis, com versos e com ação crítica, alicerçou e estimulou toda a produção do período. Em mais de um momento - "A Nova Geração" (1879), "Prefácio às Sinfonias" (1882) de Raimundo Correia ou "Prefácio às Meridionais" (1884) de Alberto de Oliveira - ele forja o modus operandi da nova poesia nacional (ASSIS, 1997). Aconselha o rigor métrico e a correção gramatical; a precisão lingüística e imagética; estimula o uso de formas fixas e semi-fixas como o triolé, o pantum, a terza rima e o rondel; pede a recuperação do soneto e da tradição lírica portuguesa. Os parnasianos nem precisariam desistir do lirismo afetivo, bastava controlar as lágrimas, enxugar o sangue, segurar os devaneios.

Segundo José Veríssimo, o soneto foi reintegrado "na poesia nacional, donde os românticos a haviam quase banido" (VERISSÍMO, 1977, p. 158). Ainda que dominassem os quatorze versos, nomes como Gonçalves Dias, Luís Gama (1830-1882), Álvares de Azevedo ou Castro Alves (1847-1871) preferiam multiplicar as estrofes ou concebê-las extensas. Prevalecem neles os médios e longos poemas, em que se consegue dissertar demoradamente sobre política, costumes, desilusões ou a terra natal. Daí o efeito, às vezes, de escrita em surto. O parnasiano quer, por seu turno, afastar do trabalho com a palavra qualquer impressão de arrebatamento. Avesso às divagações, seus quadros ficam melhor circunscritos num soneto em que, mais que 
no verso corrido, o poeta consegue controlar a linguagem. Nas palavras de Antonio Carlos Secchin, "a preferência pelo soneto é estratégia que confirma o apego por uma forma estável e fixa como suporte adequado de representação de uma realidade também fixa e ordenada" (SECCHIN, 2004, p. 196).

$\mathrm{Na}$ lírica de línguas modernas, talvez não haja forma fixa que vença o soneto em fama e dificuldade de execução. "O Soneto, conceitua Raphael Bluteau ainda no início do século XVIII, é a obra mais dificultosa da Poesia, pelas regras, que na composição dela se hão de observar com rigorosa exacção, e até com escrúpulo" (BLUTEAU, 1720, p. 721). Em português, Camões (1525?-1580?) ajudou a notabilizar o modelo considerado clássico a partir do qual parece derivar as demais variantes. Metro: decassílabo, ou hendecassílabo, desconsiderando a reforma atribuída a Antonio Feliciano de Castilho (1800-1975). Estrofação: dois quartetos e dois tercetos. Esquema de rimas: abba/abba/cdc/dcd. Quanto ao conteúdo, na primeira estrofe "o poeta põe a tese, na segunda explana", na terceira "confirma a tese", no quarto "conclui” (CARVALHO, 1991, pp. 104-105). Glauco Mattoso acrescenta que independente de "seu teor, conceitualmente o soneto se resolve como um raciocínio filosófico, no qual as premissas enunciadas nos quartetos conduzem matematicamente às conclusões dum silogismo poético cujo último verso leva apropriadamente a denominação 'chave de ouro'” (MATTOSO, 2004).

Artur Azevedo observava essas regras gerais do soneto clássico. Em "Conseqüências", reiterando a conhecida inflexão cômica, acerta todos os decassílabos, encaixa rima por rima, delineia a matéria com evidente lógica argumentativa. Como uma rubrica que lemos ao início de uma peça, o poeta ridiculariza a rotina causaconseqüência dos que se apaixonam, se casam e geram filhos. Primeiro o namoro (tempo dos desejos), depois o casamento (tempo do amor) e, por fim, a expansão da nova família.

\section{Conseqüência}

Há cinco meses já que estão casados.

Da lua de mel os últimos lampejos

Gozam, trocando aborrecidos beijos,

Numa larga poltrona acomodados.

Falam do tempo em que eram namorados...

Tempo menos de amor que dos desejos...

Separam-se, afinal e entre bocejos,

Ele fuma... ela borda... ambos calados. 
De repente ela se ergue e o rosto esconde, Saltando um grito estrídulo, indiscreto.

Ao que o eco da sala corresponde.

Ele interroga-a pálido, inquieto...

Ela trêmula e rubra lhe responde...

Sente no seio remexer-se um feto.

(AZEVEDO, 1909)

O trânsito entre processos dramáticos e líricos não representa nenhuma novidade. Veja-se, para ficar entre contemporâneos de Artur Azevedo, "Uma Ode de Anacreonte" de Machado de Assis, ou "O Juramento" de Raimundo Correia. A maneira, no entanto, como Artur põe em andamento a cena acima, revela aquilo que me parece ser sua contribuição e não apenas para o parnasianismo: associada à comicidade, a execução sui generis de técnicas teatrais dentro do soneto. Trata-se de um desafio complexo, dado que a inclusão de novidades nesse terreno regrado não deve, ao mesmo tempo, desfigurá-lo. Nos limites dos quatorze versos o engenho se move dentro da norma, qualquer acréscimo ou movimento mal sucedido pode caracterizar a falta de técnica do sonetista.

Artur Azevedo vence os perigos porque, prudente, acomoda apenas dois recursos comuns ao texto teatral, os quais nem sempre aparecerão juntos em seus sonetos. O diálogo: interlocução direta entre personagens, procedimento definidor da ação dramática em contraposição às formas essencialmente narrativas (ROLIM, 2005). A didascália: impronunciadas pelos personagens, instruções sobre a encenação que o dramaturgo espalha para atores, diretores, cenógrafos e outros agentes envolvidos na montagem da peça (MENDES, 2005). Nos sonetos de Artur, pela impossibilidade de encenação, tais indicações realizam-se na imaginação. Mais do que em peças cujos cenários descritos são "inexecutáveis", os dados dramáticos desses sonetos são, no limite, absolutamente literários (OITITICA, 1960, p. 291).

Radicado na matriz clássica, o soneto abaixo é todo composto, ao mesmo tempo, de didascálias e diálogos. À função de crítico teatral, uma das principais ocupações de Artur Azevedo, soma-se aqui a impassibilidade parnasiana. Se uma resenha, mesmo que impressionista, busca impessoalidade diante da matéria examinada, certo parnasianismo extremado refreia o eu lírico subjetivo que, por definição, se deixa afetar pelo tema. Amiga do soneto, filho natural da lírica, tal vertente achou no estilo épico a objetividade de que precisava para escapar às fusões exageradas entre sujeito e objeto. Para conseguir tal distanciamento antilírico - exemplar no Bilac de Panóplias (1988) - Artur preferiu recorrer a teatro, no qual os acontecimentos parecem evoluir por si, porque sem persona poética ou narrador. 
IMPRESSÕES DE TEATRO

A Guimarães Passos

Que dramalhão! Um intrigante ousado, Vendo chegar da Palestina o conde, Diz-lhe que a pobre da condessa esconde

No seio o fruto de um amor culpado.

Naturalmente o conde fica irado, - “O pai quem é?" pergunta. - "Eu!", lhe responde

Um pajem que entra. - "Um duelo!" - "Sim! Quando? Onde?"

No encontro morre o amante desgraçado.

Folga o intrigante... Porém surge o mano, E vendo morto o irmão, perde a cabeça, Crava o punhal no peito tirano.

É preso o mano, mata-se a condessa, Endoidece o marido... e cai o pano, Antes que outra catástrofe aconteça.

(AZEVEDO, 1914)

Satiriza-se o formato dos dramalhões, no caso, os de capa e espada. No primeiro quarteto, temos a apresentação do assunto medieval: ao retornar de uma cruzada, o nobre cristão recebe a informação de que sua esposa está grávida de outro. No segundo, conhecemos, com o Duque, o pai da criança, sobre o qual cai a fúria do marido traído. No primeiro terceto, o delator é vingado pelo irmão do assassinado. No segundo, a condessa suicida-se, afinal, tiraram-lhe o amor. Já o nobre termina sozinho e enlouquecido, eis a recompensa para quem descuidou da família para ir brigar com os sarracenos.

Com excessos sentimentais, lances de violência às vezes gratuita, embates maniqueístas, o dramalhão conquistou enorme popularidade a partir do século XIX. Artur Azevedo costumava abrir fogo contra ele. Como crítico ou comediógrafo "nunca escondeu a preferência pela opereta e pela revista", gêneros também de sucesso, porém considerados superiores ao que taxava de "dramalhões pantafaçudos" (FARIA, 2001, pp. 171-179). No soneto em questão, a invectiva contra o paradigma melodramático elabora-se dentro da própria arena literária. Crítico e poeta lutam na mesma trincheira. De modo semelhante procedera Almeida Garrett (1799-1854) quando usou o romance para descortinar a receita da "originalidade" romântica. Sem estudo ou talento, mas dependente de público, bastaria ao dramaturgo ou ao romancista o seguinte padrão de roteiro: "Uma ou duas damas, / Um pai, / Dois ou três 
filhos, de dezenove a trinta anos, / Um criado velho, / Um mostro, encarregado de fazer maldades, / Vários farsantes, e algumas pessoas capazes para intermédios" (GARRET, s/d, p. 36).

Dramaturgo e poeta engenhoso, Artur Azevedo conseguiu levar a arte do soneto dramático ao virtuosismo. Seu "Soneto Dramático" arranja com destreza as seções de um espetáculo. Primeiro quarteto: exposição do assunto (incesto) e o primeiro ato, em que o cavalheiro galanteia a senhora. Segundo quarteto: segundo ato, em que o barão descobre tudo e quer lavar a honra. Primeiro terceto: terceiro ato, em que o barão encontra e vai matar o rapaz que apaixonou sua esposa. Segundo terceto: conclusão, reconhecimento e desenlace da história, em que barão e cavalheiro se descobrem pai e filho. A chave de ouro (desfecho em grande estilo) ainda aclama o dramaturgo, convocando-o ao palco para os aplausos da platéia.

Soneto Dramático

O Incesto. Drama em 3 atos. Ato primeiro: Jardim. Velho castelo iluminado ao fundo. O cavalheiro jura um casto amor profundo, E a castelã resiste... Um fâmulo matreiro

Vem dizer que o barão suspeita o cavalheiro... Ele foge, ela grita... - Apito! - Ato segundo: Num salão do castelo. O barão, iracundo, Sabe tudo... Horror! Vingança! - Ato terceiro:

Em casa do galã, que, sentado, trabalha, Entra o barão armado e diz: "Morre, tirano, Que me roubaste a honra e me roubaste o amor!"

O mancebo, descobre o peito: "Uma medalha! Quem t'a deu?! - Minha mãe - Meu filho! - Cai o pano... À cena o autor! À cena o autor! À cena autor!

\section{(AZEVEDO, 1909)}

O poeta reúne nesses versos algumas das técnicas definidoras do artífice parnasiano maiúsculo: domínio do verso alexandrino, da chave de outro e do soneto. Espécie de síntese da poética parnasiana brasileira, o Tratado de Versificação de Olavo Bilac e Guimarães Passo (1867-1906) estabelece o alexandrino clássico como o "mais difícil de manejar" (BILAC; PASSOS, 1949, p. 67), provavelmente porque, àquela altura, ainda recém acomodado à tradição do idioma. Já a chave de ouro deveria encerrar "a essência do pensamento geral da composição" (Idem, p. 165). Quanto 
ao soneto, basta constatar que restabelecem uma das regras da Arte Poética de Boileau (1636-1711) ditada, inclusive, em alexandrino: "un sonnet sans défaut vaut seul un long poëme” (Idem, p. 166).

O arremate do "Soneto Dramático" volta o holofote para o autor do hipotético dramalhão, que cai nos braços de uma audiência à beira da convulsão. No limite, porém, vem à cena Artur Azevedo que, senhor da arte dramática, sublinha a facilidade do receituário do gênero ridicularizado. Com propriedade, a chave de ouro provoca aquela "explosão teatral” que José Guilherme Merquior depreciou nos sonetos parnasianos (MERQUIOR, 1977, p. 127). Em certo sentido, a arte do soneto dramático pode ser encarada como desdobramento, na lírica, daquilo que Larissa Neves detectou como "metateatro" na peça O Mambembe, do próprio Artur, em que o "fio condutor da trama consiste em fazer passar por realidade episódios tradicionais da simbologia teatral” (NEVES, 2006, p. 204).

Um dos desígnios parnasianos era retomar a fonte primeira da lírica, classicamente localizada na Grécia antiga. O célebre "Vaso Grego" alegoriza essa busca no suposto berço da poesia originada para deleite do Olimpo, cantada e tocada por Apolo e pelas Musas, só mais tarde concedida ao primitivo homem-poeta que Alberto de Oliveira identificou em Anacreonte (séc. VI a.C.), chamado por isso de "novo deus". Mas o parnasianismo alterou a idéia antiga de inspiração, em lugar de aceitá-la, sai a sua conquista. Reformulando a tradição narrada por Hesíodo (séc. VIII a.C.) "Pelas Musas e pelo golpeante Apolo / há cantores e citaristas sobre a terra, / e por Zeus, reis. Feliz é quem as Musas / amam, doce de sua boca flui a voz." (HESÍODO, 2003, p. 111) - , o dom poético resulta agora da faina com as palavras e com a cultura.

Artur Azevedo, a seu modo, realiza a viagem à antiguidade helênica. Sua arte do soneto dramático sugere a possibilidade de (re)união da lírica com o teatro. Ora, Aristóteles definia a comédia como a imitação de homens inferiores ou em ações ridículas. Quanto à origem, o gênero descenderia "dos solistas dos cantos fálicos" (ARISTÓTELES, 1973, pp. 446-447). Nascida da lírica, portanto, Artur devolve a comédia aos braços da antiga mãe. Consegue, ao mesmo tempo, acrescentar uma terceira dimensão ao universo do soneto, à medida que transforma o campo horizontal (ritmo e pensamento) dos catorze versos em tablado (ritmo, pensamento e espetáculo).

\section{Bibliografia}

ASSIS, Machado de., Crítica e variedades. São Paulo: Globo, 1997.

ARISTÓTELES, Poética. Tradução e comentários de Eudoro de Souza. In: Os Pensadores. São Paulo: Abril Cultural, 1973.

AZEVEDO, Artur. Rimas. Recolhidas dos jornais, revistas e outras publicações por Xavier Pinheiro. Rio de Janeiro: Companhia Industrial Americana, 1909.

. Sonetos e Peças Líricas. Organização de Júlio de Freitas J. Rio de Janeiro: Livraria Garnier, 1914.

BANDEIRA, Manuel. Antologia dos Poetas Brasileiros da Fase Parnasiana. Rio de Janeiro: Ministério da Educação e Saúde, 1938.

BARROS, Jayme de. Poetas do Brasil. Rio de Janeiro: José Olympio, 1944. 
BILAC, Olavo; Passos, Guimarães. Tratado de versificação. Rio de Janeiro: Livraria Francisco Alves, 1949.

BLUTEAU, Raphael. Vocabulário português e latino. Lisboa: Na Oficina de Pascoal da Silva, v.7, 1720. Edição em CD-ROM. Rio de Janeiro: UERJ, Departamento Cultural, 2000.

BOSI, Alfredo. História concisa da literatura brasileira. São Paulo: Cultrix, 1994.

CARVALHO, Amorim de. Tratado de versificação portuguesa. Coimbra: Livraria Almedina, 1991.

FARIA, João Roberto. Idéias teatrais: o século XIX no Brasil. São Paulo: Perspectiva/Fapesp, 2001.

FRANCHETTI, Paulo. Estudos de literatura brasileira e portuguesa. Cotia SP: Ateliê Editorial, 2007.

GARRET, Almeida. Viagens na minha terra. Edição dirigida e apresentada por Antônio Soares Amora. Rio de Janeiro: Ediouro, s / d.

HESÍODO. Teogonia: a origem dos deuses. Edição bilíngüe. Estudo e tradução de Jaa Torrano. São Paulo: Iluminuras, 2003.

IVO, Lêdo. “Os Navios parnasianos”. In: JunQueIRA, Ivan (Org.). Escolas literárias no Brasil - Tomo II. Rio de Janeiro: Academia Brasileira de Letras, 2004. Ou CríticaECompanhia, on-line: http:// www.criticaecompanhia.com/ledo.htm. Acessado em: 30 mar. 2005.

JÚNIOR, Carvalho. Parisina (Teatro, Versos, Folhetins, Crítica Literária e Escritos Políticos). Rio de Janeiro: Tipografia de Agostinho Gonçalves Guimarães e Cia., 1879.

MATTOSO, Glauco. Site Oficial.

On-line: http://glaucomattoso.sites.uol.com.br/teoriadosoneto.htm. Acessado em 20 ago. 2004.

MENDES, Alice. "Didascália". In: E-Dicionário de Termos Literários. Coordenação de Carlos Ceia. 2005. On-line: http://www.fcsh.unl.pt/edtl/verbetes/D/didascalia.htm. Acessado em 04 abr. 2008.

MERQUIOR, José Guilherme. De Anchieta a Euclides. Rio de Janeiro: José Olympio, 1977.

NEVES, Larissa de Oliveira. As Comédias de Artur Azevedo: em busca da história. Tese de doutorado. Campinas: IEL-UNICAMP, 2006.

OITITICA, José. Curso de literatura. Coligido e revisto por Roberto das Neves. Rio de Janeiro: Editora Germinal, 1960.

PACHECO, João. O Realismo(1870-1900): vol. III. São Paulo: Cultrix, s/d.

ROLIM, Rita. "Diálogo". In: E-Dicionário de Termos Literários. Coordenação de Carlos Ceia. 2005. Online: http://www.fcsh.unl.pt/edtl/verbetes/D/dialogo.htm. Acessado em 04 abr. 2008.

SECCHIN, Antonio Carlos. "Presença do Parnaso". In: JunQueIra, Ivan (Org.). Escolas literárias no Brasil - Tomo II. Rio de Janeiro: Academia Brasileira de Letras, 2004.

STEGAGNO-PICCHIO, Luciana. História da literatura brasileira. Rio de Janeiro: Lacerda Editores / Academia Brasileira de Letras, 2004.

SILVA RAMOS, Péricles Eugênio da. Poesia Parnasiana - Antologia. São Paulo: Melhoramentos, 1967.

SODRÉ, Nelson Werneck. História da literatura brasileira: seus fundamentos econômicos. Rio de Janeiro: Civilização Brasileira, 1964.

TEIXEIRA, Ivan. "Prefácio: em defesa da poesia (Bilaquiana)". In Bilac, Olavo. Poesias. São Paulo: Martins Fontes, 1997.

VERÍSSIMO, José. Estudos de literatura brasileira: $2^{a}$ série. Introdução de Vivaldi Moreira. Belo Horizonte / São Paulo: Itatiaia / EDUSP, 1977. 